\title{
Urgences
}

\section{Des économies pour la culture}

\section{Catherine Franche}

Numéro 9, 1er trimestre 1984

URI : https://id.erudit.org/iderudit/025131ar

DOI : https://doi.org/10.7202/025131ar

Aller au sommaire du numéro

Éditeur(s)

Urgences

ISSN

0226-9554 (imprimé)

1927-3924 (numérique)

Découvrir la revue

Citer cet article

Franche, C. (1984). Des économies pour la culture. Urgences, (9), 7-14.

https://doi.org/10.7202/025131ar

Ce document est protégé par la loi sur le droit d'auteur. L'utilisation des services d'Érudit (y compris la reproduction) est assujettie à sa politique d'utilisation que vous pouvez consulter en ligne.

https://apropos.erudit.org/fr/usagers/politique-dutilisation/
Cet article est diffusé et préservé par Érudit.

Érudit est un consortium interuniversitaire sans but lucratif composé de l'Université de Montréal, l'Université Laval et l'Université du Québec à Montréal. Il a pour mission la promotion et la valorisation de la recherche. https://www.erudit.org/fr/ 


\section{CHRONIQUE}

\section{DES ÉCONOMIES POUR LA CULTURE}

PAR

CATHERINE FRANCHE 


\section{DES ÉCONOMIES POUR LA CULTURE}

Nous dissocions souvent économie et culture. Nous relèverons la première avant de nous occuper de la deuxième. Mais ces deux pôles sont-ils si éloignés l'un de l'autre. La société n'est-elle pas beaucoup plus complexe, plus intégrée? Une approche systématique et plus globale des problèmes est de rigueur. Économie et culture vont de pair.

C'est en faisant preuve de créativité et d'imagination, en inventant de nouveaux échanges, le tout à partir de notre histoire, de ce que nous sommes, que nous pourrons progresser. C'est en utilisant notre culture, notre "savoir être" que nous prendrons ces fameux virages, technologique ou autres.

La culture a effectivement des retombées sur l'économie et sur la vie des gens. Mentionnons, à titre d'exemple, l'impact économique direct, en masse salariale, de l'entreprise culturelle dans l'Est du Québec. En 1981, 689 travailleurs et travailleuses étaient rémunérés(es) par le domaine culturel. De ce nombre, 363 travaillaient à temps complet. Avec un salaire moyene de $15000 \$$ par année, l'entreprise culturelle versait à ces individus 5445000 en salaires. Et cela sans compter les travailleurs et les travailleuses à temps partiel.(1) Ces données ont été établies sur la base du nombre de répondants, ce qui constitue une vue partielle de la réalité d'ensemble.

De plus, si nous nous fions à un rapport produit par I'Université de Victoria sur l'impact économique des organismes culturels à but non-lucratif, nous pouvons, pour chaque dollar retourné dans le milieu, appliquer un "multiplicateur de revenu" de 2,5. Chaque dollar de revenu, par le roulement qu'il produira, est en fait un générateur économique 2,5 fois supérieur. (2)

Par ailleurs, toute production culturelle nécessite un minimum de conditions économiques favorables. Voilà pourquoi La Savoyane, Fondation pour la Culture de l'Est du Québec, a choisi de stimuler la culture en lui apportant une aide financière. 


\section{Dans I'Est}

La situation économique de la culture dans l'Est du Québec n'est pas plus rose ni probablement plus grise qu'ailleurs. La vie d'artiste, un portrait de la situation économique des producteurs et des productrices en arts visuels de I'Est du Québec, préparé par le Conseil de la Culture, en témoignait en 1981. À titre d'exemple, le salaire annuel moyen tiré de la production d'un créateur en arts visuels, était en 1979, de 2900 \$. C'était, même il y a 4 ans, largement insuffisant pour vivre décemment.(3)

Tous les travailleurs et toutes les travailleuses culturels(les) sont conscients de la situation financière de la culture dans I'Est pour l'avoir vécue. Rien ne sert d'élaborer là-dessus.

Ce n'est pas d'hier que l'Est du Québec revendique, face à I'État, une plus grande autonomie - décisionnelle et budgétaire - dans le but de gérer son développement social, économique et culturel.

Depuis plusieurs années nous parlons de régionalisation, d'appropriation par les gens de la région des moyens financiers pouvant stimuler le développement de la culture régionale. Qu'on relise les compte-rendus des colloques tenus en 1978 dans 8 territoires de l'Est du Québec. Ainsi, cet extrait du rapport de la Mitis: "les groupes et organismes du milieu revendiquent le rapatriement des moyens de production et de diffusion culturelle et le pouvoir d'administrer de façon autonome, des budgets affectés au développement des traits spécifiques à leur sous-région".(4)

Faut-il encore espérer de l'État la création d'organismes réellement indépendants, dirigés par les régions? Un éveil, une prise en main par une communauté de son devenir culturel équivalent à une ouverture d'esprit, à une meilleure compréhension du monde et conséquemment, à une critique plus juste de son environnement politique et social. Tout cela 
est utile à l'État tant et aussi longtemps qu'il en garde le contrôle.

Quand on crie partout sur les ondes qu'un homme sans savoir et sans culture vaut mieux qu'un homme savant, il faut (...) demander: mieux pour qui?(5)

Ne dénigrons pas le rôle de l'État dans la culture: il a pris la place de mécène que tenait l'Église dès l'époque romaine. Ce rôle est important, mais soyons tout de même conscients que l'État ne répondra jamais tout à fait aux aspirations des populations.

Issue de ces considérations, la Fondation pour la Culture de I'Est du Québec, La Savoyane, voyait le jour en mars 1981.

\section{La Savoyane}

La Savoyane a été créée dans le but de devenir un outil de notre développement culturel, ne dépendant pas ou peu des différents paliers gouvernementaux. Un outil conçu et contrôlé par tous ceux et celles qui se sentent concernés(es) par la culture de l'Est du Québec.

La Savoyane a été fondée sur le principe même que toute forme de promotion de la culture - recherche, création ou diffusion - doit se faire dans des conditions économiques respectables. C'est pourquoi le principal moyen choisi, afin d'encourager l'essor culturel, est l'attribution d'une aide financière à des intervenants culturels.

Ainsi, la Fondation attribue à chaque année une ou plusieurs bourses à des individus ou à des organismes oeuvrant dans le domaine de la culture, dans l'Est du Québec.

Ces bourses proviennent des intérêts des fonds recueillis par La Savoyane, à chaque année, lors d'une campagne de souscription menée essentiellement dans le Bas-Saint- 
Laurent, la Gaspésie et les Iles-de-la-Madeleine. Ainsi le capital amassé demeure intact et fructifie d'année en année. Dans dix, vingt ans d'ici, la Fondation sera encore présente dans I'Est du Québec et sera d'autant plus un catalyseur culturel que ses fonds se seront accrus, lui permettant ainsi une plus grande contribution à la culture régionale.

Une telle Fondation est donc une entreprise à long terme. C'est petit à petit qu'un capital important sera amassé et que son impact économique sur le développement culturel se fera ressentir. Entreprise longue, mais sûre toutefois. L'argent confié par le milieu à La Savoyane restera toujours intact dans ses coffres. Seuls les intérêts seront distribués et serviront à promouvoir la culture régionale. En fait la Fondation, tout comme les autres organismes de cette nature, ne peut utiliser plus de $15 \%$ de l'argent récolté à des fins administratives.

II est intéressant de noter la symbolique attribuée à la plante qu'est la savoyane, fleur abondamment présente dans tout l'Est du Québec, et par extension à la Fondation. Selon le Dictionnaire des symboles: "La plante symbolise I'énergie solaire condensée et manifestée... La plante, premier degré de la vie, symbolise surtout la naissance perpétuelle, le flux incessant de l'énergie vitale."(6)

La Savoyane concentre les énergies monétaires du milieu et les y retourne périodiquement.

\section{Réalisations et projets}

À ce jour, La Savoyane a su récolter $19000 \$$ placés à moyen et à long termes entre les mains d'une institution financière de la région. Considérant le peu de place que tient souvent la culture dans les préoccupations d'une bonne part de la population, $20000 \$$ en un peu plus de 2 ans, c'est tout de même bien! D'autant plus que La Savoyane a su bénéficier de plusieurs programmes gouvernementaux de création d'emplois qui lui ont permis d'embaucher régulièrement du personnel, assurant ainsi une permanence pendant une grande partie de l'année. 
Le capital amassé le fut en bonne partie grâce à la tenue de deux encans-profits d'oeuvres d'art, oeuvres qui avaient toutes été généreusement données à la Savoyane par des artistes de la région. Un événement sans précédent dans notre région; une collaboration des artistes vraiment remarquable.

L'an dernier, La Savoyane attribuait ses deux premières bourses: I'une à un individu de Bonaventure, M. Jean Gauthier, pour une série d'exposés dans quatre polyvalentes sur l'histoire régionale de la Gaspésie; I'autre, à un organisme de la partie sud de la Matapédie, la Société I'Angélus, qui démarrait ses actions en vue d'obtenir l'implantation d'un centre culturel à Saint-Alexis-de-Matapédia.

Cette année, La Savoyane veut se régionaliser et mettre sur pied des comités locaux dans 3 ou 4 des sous-régions de I'Est du Québec. Ces comités locaux feront partie intégrante de la Fondation, de ses décisions, récolteront de l'argent dans leur milieu pour ensuite remettre leurs propres bourses. La Savoyane entend ainsi donner la parole et le pouvoir aux individus des sous-régions. La Savoyane compte établir une régionalisation réelle, effective et croit qu'une telle action aura pour effet non seulement de multiplier les énergies qui lui seront disponibles, mais également de stimuler l'essor culturel des sous-régions. II semble vraisemblable qu'une régionalisation des pouvoirs et des sommes augmentera l'intérêt du milieu face à son développement culturel.

La fondation pour la Culture de l'Est du Québec provient d'un besoin ressenti et exprimé dans notre région, de la volonté de cesser de marginaliser la culture et ses intervenants: tous deux exigent, comme tous les autres secteurs de la société, des conditions économiques "normales" pour proliférer. Après maintes réflexions, il est apparu évident qu'une intervention financière culturelle dépendante de l'État, d'une part, ne satisferait que partiellement les besoins régionaux et, d'autre part, serait constamment sujette à des changements selon les politiques gouvernementales établies. 


\section{NOTES:}

(1) Profil économique des entreprises culturelles de l'Est du Québec, Étude descriptive, Conseil de la Culture de I'Est du Québec, chargées de recherche: Ginette Lepage et Mireille Perreault, sept. 1981.

(2) Economic impact of non-profit arts organizations in British Columbia, A report by the Centre for Public Sector Studies, University of Victoria for Cultural Services Branch, Ministry of Provincial Secretary and Government Services.

(3) La vie d'artiste ou portrait d'ensemble de la situation économique des producteurs et des productrices en arts visuels de l'Est du Québec, Conseil de la Culture de l'est, chargée de recherche: Ginette Lepage, février 1981, p. 44.

(4) Les colloques culturels de l'Est du Québec, Rapport final, Conseil de la Culture de l'Est du Québec, 1978, p. 85, 86.

(5) Bertolt Brecht, Art et politique, L'Arche, 1967, p. 13.

(6) Jean Chevalier, Alain Gheerbrant, Dictionnaire des symboles, Robert Laffont/Jupiter, 1982, p. 764. 


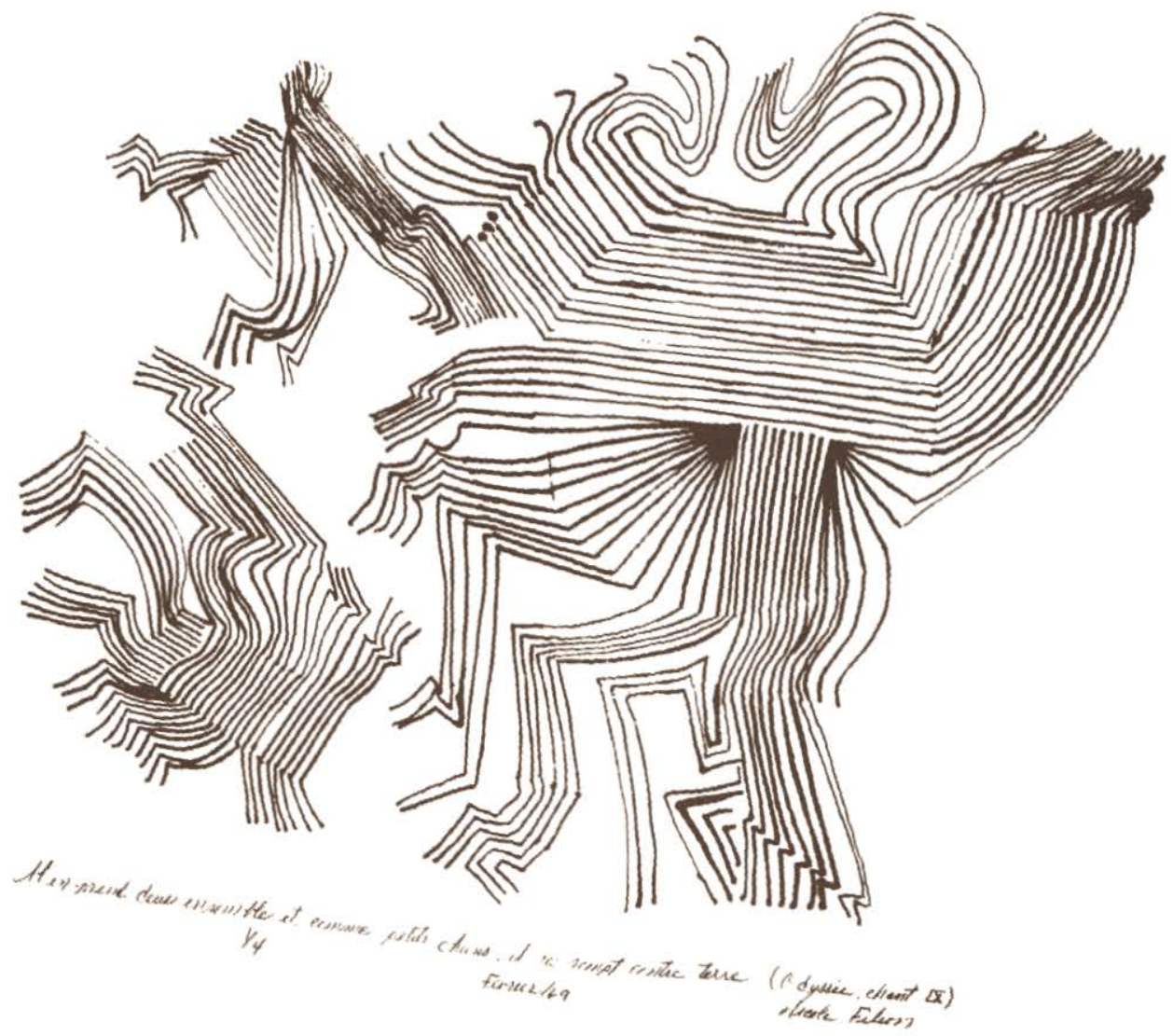

